\title{
SOBERANÍA POPULAR Y "MOMENTO CONSTITUYENTE” EN EL DEBATE SOBRE CAMBIO CONSTITUCIONAL EN CHILE
}

Claudia Heiss Bendersky 


\section{CLAUDIA HEISS BENDERSKY}

Profesora Asistente del Instituto de Asuntos Públicos de la Universidad de Chile e investigadora del Centro de Estudios de Conflicto y Cohesión Social (COES). Doctora en Ciencia Política por la New School for Social Research, Magíster por la Universidad de Columbia, becaria Fulbright y periodista por la Universidad de Chile, presidió entre 2012 y 2014 la Asociación Chilena de Ciencia Política. Sus investigaciones recientes se centran en el constitucionalismo latinoamericano, el cambio constitucional en Chile y el desarrollo de la ciencia política. 


\section{SOBERANÍA POPULAR Y "MOMENTO CONSTITUYENTE” EN EL DEBATE SOBRE CAMBIO CONSTITUCIONAL EN CHILE}

\section{INTRODUCCIÓN}

La mayor parte de las transiciones a la democracia ocurridas en décadas recientes en América Latina vino acompañada de procesos de reemplazo constitucional. En Chile, las fuerzas opositoras al régimen militar contemplaban desde muy temprano este tema como un punto central de su agenda democratizadora. La vía negociada de la transición, sin embargo, determinó que se postergara y fuera finalmente reemplazado por un acomodo de las fuerzas políticas vencedoras en el plebiscito de 1988 a las reglas establecidas por el gobierno saliente. Este proceso implicó una serie de reformas, partiendo por la reforma constitucional de 1989, que hizo posible el tránsito hacia un nuevo gobierno, y más tarde las reformas de 2005, que lograron importantes avances en la construcción de una institucionalidad más compatible con la democracia. A pesar de ellas, sin embargo, el problema constitucional en Chile, lejos de desvanecerse, ha recrudecido en años recientes. El descontento ciudadano frente a un modelo político incapaz de responder a las preferencias electorales ha contribuido a alimentar el creciente distanciamiento entre sociedad e instituciones que amenaza hoy la legitimidad del sistema político en su conjunto.

En lo que sigue, se plantea que resolver el problema constitucional es esencial para reconstruir un sistema político capaz de dar respuesta a las demandas de la sociedad. La primera sección describe tres visiones diferentes en torno al cambio constitucional: a) el rechazo de la derecha a una nueva Carta Fundamental, b) la vía de reformas que, dentro de la actual institucionalidad, reduzcan el déficit democrático legado por la dictadura, y c) la propuesta de una nueva Constitución elaborada en forma democrática y participativa. La segunda sección del artículo analiza la iniciativa constitucional anunciada por el gobierno en 2015 y lo que va de su aplicación: un proceso caracterizado por su longitud en el tiempo y por abrir más que cerrar vías de implementación. En la tercera parte se discute el concepto de "momento constituyente" como espacio de activación de la soberanía popular, requisito para poner en marcha un cambio profundo del ordenamiento político. Por último, se discute el problema de los derechos económicos y sociales como parte central de un acuerdo alternativo al consagrado en la Constitución de 1980. 


\section{VISIONES SOBRE EL CAMBIO CONSTITUCIONAL EN CHILE}

¿Necesita Chile una nueva Constitución? Entre quienes sostienen que no la necesita están los defensores del legado refundacional de la dictadura. Para ellos la Constitución de 1980 ha permitido estabilidad, crecimiento económico y ha reemplazado el papel pernicioso de la política y los partidos de los años ' 60 y ${ }^{`} 70$ por un modelo centrado en el mercado como primera preocupación de los individuos y como principal asignador de recursos:

(...) tras la extraordinaria convergencia y pacificación que se dio a fines de la década de los 1980 -a lo que se añadieron dos plebiscitos-, ella (la Constitución) fue una piedra fundacional de la reconstrucción de la democracia posible. Quedaba atrás el abismo de 1973. Los 26 años de vigencia real de la Constitución de 1980 no por casualidad coinciden con el mejor período de la historia del país desde fines del XIX" (Joaquín Fermandois, "Danza Constitucional", El Mercurio, 10/05/2016).

Las reformas constitucionales de las últimas décadas son, desde esta perspectiva, un retroceso, aunque aún valdría la pena defender hasta donde sea posible el proyecto institucional de Pinochet y Jaime Guzmán. Esta perspectiva es heredera de la idea de democracia "protegida" o "tutelada" anunciada por Pinochet en el discurso del Cerro Chacarillas de 1977. Se trata de una forma política distinta de la democracia representativa (Godoy, 1999) y que revela importantes continuidades con el autoritarismo (Huneeus, 1997):

(...) la mayor parte de la derecha recela del contenido de una nueva Constitución, mira con temor las propuestas que se han hecho en el sentido de revisar el derecho de propiedad con una goma y los derechos económicos y sociales con un lápiz (...) Parte relevante de la derecha de este país recela de la democracia participativa, vale decir, recela de las mayorías, porque tiene un fuerte trauma con la Unidad Popular, y sigue prefiriendo una democracia protegida" (Correa Sutil 2015: 58).

A través de editoriales y columnas en medios de comunicación como los diarios La Tercera y El Mercurio, este sector rechazó desde el comienzo la discusión constitucional argumentando que se trataba de una maniobra de ciertos líderes políticos para instalar un debate artificial: 
En la actual coyuntura política, no se vislumbra una conmoción de importancia que ponga en peligro las estructuras del Estado (...) Salvo cuestiones más bien puntuales, la Constitución de 1980, especialmente en materia de derechos fundamentales, parece interpretar el sentir ciudadano. No se percibe un clamor social efectivo capaz de desencadenar grandes transformaciones, a pesar de todos los esfuerzos que algunos sectores realizan para aparentarlo" (Pablo Rodríguez, "Falso escenario constitucional, El Mercurio, 29/05/2015).

Se argumentó que esta discusión generaba incertidumbre jurídica, poniendo en riesgo las inversiones y la estabilidad económica, y que el debate constitucional era demasiado complejo para someterlo a la ciudadanía:

La experiencia ya demostrada en aquel proceso da cuenta de gente que se reúne a conversar, con base en pautas amplísimas y que no tiene claro para qué se los convoca, ni cuál es el objetivo de tales encuentros, menos aún lucidez en la formulación de conclusiones. Se trata de personas que no han leído siquiera en parte la Constitución y a quienes se les insta a mejorarla. Resulta insólito que puedan ser convocados a opinar sobre tan complejos y transcendentales temas personas desde los catorce años de edad" (José Luis Cea Egaña, "Una mirada al proceso pre-constituyente, El Mercurio, 03/07/2016).

Un segundo grupo que considera que el país no necesita una nueva Constitución es aquel que, rechazando el proyecto político de la dictadura, sostiene que la actual Carta Fundamental se ha ido democratizando y continuará haciéndolo por la vía de reformas graduales negociadas dentro del marco institucional vigente. Si la primera respuesta es propia de grupos de la derecha, especialmente aquellos cercanos a la UDI, la segunda posición es compartida por segmentos de la derecha más democrática, grupos liberales y del centro político, sectores que reivindican el legado de la transición y su capacidad democratizadora incremental (Fuentes y Joignant, 2015: 111).

Esta segunda posición parece refrendada por importantes transformaciones políticas que han sucedido durante los últimos años. Chile ha sufrido cambios innegables que incluyen, por ejemplo, la aprobación de una ley de divorcio, la regulación de las parejas de hecho por medio de la unión civil, la ley antidiscriminación o la ampliación de cobertura de salud a través del Plan Auge. Junto con esas y otras modificaciones de relevancia social, las reformas constitucionales de 2005 fueron un hito democratizador al eliminar los senadores designados y el rol político que daba a la Fuerzas Armadas el Consejo de Seguridad Nacional. La reforma legal 
de 2015 que reemplazó el sistema binominal, fuertemente distorsionador de las preferencias electorales, por un régimen proporcional, fue un avance en el mismo sentido. Algo que parecía inamovible de pronto fue removido.

En todos estos casos, sin embargo, los cambios políticos fueron producto de acuerdos que lograron concitar el apoyo de sectores de la derecha cuyas posiciones se encuentran "subsidiadas" en el sistema político por un poder de veto garantizado por el entramado institucional de la propia Constitución de 1980. De allí la posición de un tercer grupo que sostiene que sí es necesaria una nueva Constitución para Chile, porque la actual contiene cerrojos insalvables que impiden la plena democratización: los altos quórums de reforma a la Constitución, las leyes orgánicas constitucionales y el rol del Tribunal Constitucional —reforzado, este último, por la reforma de 2005 (Atria, 2013). Sin importar la adhesión popular que despierte la modificación de ciertas materias, ellas son refractarias a la voluntad popular gracias al poder de veto otorgado a la derecha por las instituciones vigentes.

No se trata, como han argumentado sus defensores, de un sistema "consociativo" al modo de algunas democracias europeas orientadas a la formación de acuerdos amplios, en el marco de sistemas electorales proporcionales para la formación del gobierno y las decisiones de política pública (Lijphart, 2000). A diferencia de ese modelo, el sistema chileno se caracteriza por imponer puntos de veto establecidos por la fuerza de las armas durante la dictadura y requerir la venia de sus herederos para reformar aspectos sustantivos. No es una rigidez consociativa y democrática, sino un sistema que quiere hacer pasar por "consenso" lo que no es otra cosa que una imposición forzada, sostenida en el tiempo por dispositivos diseñados para mantener el statu quo.

Quienes sostienen la necesidad de crear una nueva Constitución que cumpla con el requisito de ser un pacto político democrático concuerdan, en general, en que la Carta vigente tiene dos problemas que no se pueden solucionar desde su propia institucionalidad: su ilegitimidad de origen y su incapacidad para permitir el normal funcionamiento de la democracia, lo que finalmente se traduce en una fuente de ilegitimidad de ejercicio. El segundo punto ha sido caracterizado como la cualidad "neutralizadora" de la voluntad popular que constituye el sello político de esta Carta Fundamental y la esencia del proyecto de largo plazo de sus fundadores (Atria, 2013).

El cuestionamiento a la legitimidad de origen tiene que ver especialmente con la dimensión simbólica que cumplen las constituciones en tanto pacto fundante de una comunidad política. Pensar que las normas de convivencia política y distribución del poder establecidas por un decreto de la Junta Militar determinan quiénes somos políticamente los chilenos es, por cierto, una razón poderosa para querer cambiar la Constitución. Sin embargo, no parece ser una razón suficiente. 
Este cuestionamiento se ha esgrimido respecto de las principales constituciones anteriores del país: las de 1833 y 1925, ambas elaboradas en un contexto de confrontación política por el bando vencedor, con apoyo de las Fuerzas Armadas y sin participación popular (Valdivia, 2010; Grez, 2015). A pesar de esta circunstancia, la Constitución de 1980 tiene, respecto de su vinculación con la voluntad popular, una característica que la diferencia de las anteriores: su cualidad neutralizadora de la voluntad popular a través de mecanismos diseñados expresamente para dar poder de veto a los herederos políticos de quienes la crearon (Atria, 2013). En otras palabras, la ilegitimidad de origen de la Constitución de 1980 es más difícil de combatir por la vía de interpretaciones y adaptaciones que la acerquen a la ciudadanía que las cartas fundamentales previas.

A pesar de que en su génesis se acercan más a lo que podría considerarse "justicia del vencedor" que a un proceso deliberativo democrático, las Constituciones de 1833 y 1925 no eran refractarias a su apropiación a través del proceso político regular. Así, las reformas constitucionales de 1871 y 1874 tendieron a moderar el poder presidencial y reflejaron una orientación liberal que era incompatible con el texto original. Del mismo modo, la Constitución de 1925 permitió, a través de la negociación política y en procesos que concitaron amplio acuerdo entre distintos sectores, reformas que hicieron posibles cambios sustanciales en el sistema político: las normas que posibilitaron la Reforma Agraria a partir del gobierno de Jorge Alessandri, el "estatuto de garantías" de 1971, o la nacionalización del cobre son ejemplos de ello. Reformas de esta envergadura son justamente lo que la Constitución de 1980 se propuso impedir.

A pesar de las numerosas modificaciones que ha sufrido la Constitución de 1980, la demanda por cambio constitucional no se ha aplacado. Por el contrario, la aprobación de las reformas de 2005 generó un notorio aumento de las mociones de reforma constitucional presentadas en el Congreso (Fuentes, 2013). Si muchos, incluido el Presidente Ricardo Lagos en ese momento, pensaron que el 2005 marcaba el fin del problema constitucional en Chile, la realidad política demostró lo contrario.

\section{UN PROCESO ABIERTO}

El camino hacia una nueva Constitución, anunciado en 2015 por la Presidenta Michelle Bachelet, se compone de una serie de iniciativas orientadas a promover el clima político que requiere un proceso de reemplazo constitucional. El diseño del llamado proceso constituyente es complejo, extendido en el tiempo y con altos niveles de incertidumbre. Sin embargo, se presenta como una oportunidad para 
abrir a la ciudadanía, de una manera semi-estructurada, el debate sobre el cambio constitucional.

La propuesta del Gobierno se compone de varias etapas: se inició con una primera fase, llamada de "educación cívica", la que fue cuestionada por la elección de imágenes que parecían infantilizar la discusión, por la escasa difusión mediática y una conceptualización conservadora de los términos. Luego vino el nombramiento del Consejo Ciudadano de Observadores, donde se buscó mantener la noción de "cuotas" por sector político. A pesar de incluir a algunos actores poco frecuentes en comisiones presidenciales, la composición del Consejo fue criticada por reproducir las distorsiones de representatividad propias del sistema político chileno, incluida la falta de paridad de género. El papel de este Consejo era dar garantías de imparcialidad respecto del proceso.

La siguiente etapa anunciada fue la de los Encuentros Locales Autoconvocados y los Cabildos Provinciales y Regionales para invitar a la ciudadanía a discutir contenidos de una nueva Constitución. Esta fase, llamada participativa, dio espacio a un proceso de educación cívica y expresión de preferencias a través del debate sobre valores y principios, derechos, deberes y responsabilidades e instituciones prioritarias en una nueva Constitución. Se dejó fuera la discusión sobre el mecanismo. Muchas personas, haciendo una inversión de tiempo muy superior al que requiere concurrir a las urnas, discutieron sobre la Constitución en contextos que no hubieran sido posibles de no existir el marco institucional provisto por las autoridades. Si bien la metodología de debate mostró falencias, la participación y el nivel de discusión fueron una señal de interés ciudadano y de importantes niveles de información.

Las fases posteriores son la sistematización de contenidos y su uso para establecer un documento llamado "Bases ciudadanas para la nueva Constitución", bajo supervisión del Consejo de Observadores. A partir de este documento se elaboraría un proyecto de ley para permitir un mecanismo de cambio constitucional, actualmente no previsto, y otro para establecer los contenidos de una nueva Constitución. Sería el nuevo Congreso, electo el 2017 —donde sólo la mitad de los senadores respondería aún al sistema binominal — el llamado a decidir el mecanismo para la elaboración de una nueva Constitución: una asamblea constituyente, una convención mixta, el Congreso o la decisión de plebiscitar esas alternativas. Por último se anuncia un plebiscito ratificatorio de la nueva Constitución. El proceso señalado deja abiertas varias posibilidades, ya que deberá ser determinado por nuevos actores políticos en el futuro gobierno de 2018.

El proceso de debate ciudadano, como se ha señalado, no corresponde propiamente a un proceso de deliberación constituyente. La fase participativa no es un proceso de elaboración constitucional donde se puedan analizar las 
"restricciones, motivaciones individuales y sistemas de agregación", como lo hace Jon Elster respecto de algunas asambleas y convenciones constituyentes (Elster, 1995: 365). Es una discusión no vinculante, entre participantes no representativos, sobre aspectos generales. Esto debería hacerlas menos confrontacionales que un momento decisorio sobre el texto constitucional. Está por verse cómo tratará la literatura estas discusiones y qué tan aplicable serála comparación con otras instancias de deliberación política. Sin embargo, el hecho de que su carácter sea más expresivo que decisorio no implica que se trate de un ejercicio inútil, como sostienen algunos críticos. Sí hace que sus implicancias sean aún imposibles de determinar. Si bien parece impreciso calificar el debate constitucional de la llamada fase participativa como un proceso constituyente, sí podría argumentarse que el proceso es reflejo de un "momento constituyente" en la sociedad chilena (Ackerman, 1991; Frank, 2010).

\section{MOMENTO CONSTITUYENTE Y SOBERANÍA POPULAR}

Contra la idea de una voluntad popular unívoca y preexistente, algunos autores han desarrollado la noción de que el pueblo "surge" como efecto de ciertas instancias en que algunos alegan, con éxito, hablar en su representación (Frank, 2010; Arato, 2011; Urbinati, 2006). La legitimidad de ese alegato sólo se puede determinar a posteriori. ¿Era la convención de Filadelfia expresión de la soberanía popular de las colonias de Norteamérica? Nadie estaba muy seguro al momento de desafiar las normas establecidas. Sólo después de los hechos la historia ha señalado a los constituyentes de esa convención como los Padres Fundadores de Estados Unidos.

El ejercicio político por parte de los poderes constituidos, que actúan en nombre de la representación, está en una permanente tensión con el poder constituyente del pueblo. En Chile, los esfuerzos por declarar a las reformas de 2005 como un nuevo pacto político chocaron con la percepción de que éstas no representaban al poder constituyente, sino los pactos de la transición encarnados en poderes constituidos. Esa fue, finalmente, la interpretación política que se dio a las reformas. A pesar de que modificaron en forma muy significativa el ordenamiento institucional, existe una percepción de que no tocaron esas parcelas vedadas al proceso democrático por la Constitución del ' 80 y, en tanto, no fueron interpretadas como una redistribución sustantiva del poder.

Jason Frank califica como "momento constituyente" al episodio inusual en que el alegato de hablar en nombre del pueblo tiene eco, se vuelve políticamente plausible y permite romper con los procedimientos de la política ordinaria sin perder el carácter de democrático (Frank, 2010). Un momento constituyente no 
es, entonces, un golpe de Estado, como argumentó Jaime Guzmán siguiendo a Carl Schmitt, al declarar que la soberanía después de 1973 residía en la Junta de Gobierno. (Ruiz-Tagle y Cristi, 2006).

La idea de momento constituyente proviene de identificar un modelo dual de constitucionalismo, donde corren por vías paralelas la política ordinaria — normas elaboradas por los representantes, principalmente en el Congreso- y la política constituyente, que pertenece al pueblo y no a su expresión institucional. La política constituyente es un fenómeno extraordinario, que ocurre con poca frecuencia y remece los cimientos mismos de los acuerdos políticos fundamentales (Ackerman, 1991). En Estados Unidos, bajo la misma Constitución de 1787, Ackerman identifica tres momentos constituyentes: la independencia; la guerra civil que terminó con la esclavitud y modificó la relación de poder entre el gobierno federal y los estados; y el New Deal, que tras la crisis de 1929 cambió sustancialmente la relación entre Estado y economía, reflejando nuevos consensos sociales. El momento constituyente es descrito como un periodo de transformación, de cambios en los valores y percepciones mayoritarias que llevan al cambio y la reinterpretación de la ley fundamental. Se trata de un hecho político que obliga a transformar demandas sociales en cambios institucionales.

En el caso de Chile, el momento constituyente tiene que ver con la masiva toma de conciencia de que la Constitución de 1980, a pesar de sus múltiples reformas, mantiene una imposibilidad fundamental de permitir el juego político equitativo, porque da poder de veto en todas las decisiones relevantes a una minoría autodesignada. No es una expresión de la soberanía popular protegida de cambios circunstanciales de la opinión mayoritaria por normas supramayoritarias y control de constitucionalidad -normas habituales del constitucionalismo liberal que son compatibles con el principio democrático-, sino expresión de la voluntad de Augusto Pinochet protegida por mecanismos de parapeto.

Desde que, con el surgimiento de la modernidad, el mandato divino dejó de cumplir una función legitimadora del poder político, la voluntad popular pasó a ser el criterio definitivo de justificación de la autoridad. Así, para el constitucionalismo moderno el poder constituyente reside en el pueblo, que es soberano. Sin embargo, Andreas Kalyvas (2005) ha observado que la teoría política, siguiendo a Jean Bodin, ha tendido a concebir la soberanía como comando; como la voz del que tiene la última palabra. Esta concepción proviene de una visión militarista propia del Imperio Romano, que entiende la soberanía como la facultad de mandar y ser obedecido. Se trata de una noción vertical y jerárquica, centrada en la posibilidad de controlar y reprimir. Contra esa perspectiva, Kalyvas propone seguir a otros autores como Thomas Paine y George Lawson para entender la soberanía como la capacidad de moldear la identidad de una comunidad política. Es decir, la soberanía 
como el poder constituyente democrático que establece las reglas de la política ordinaria.

Kalyvas enfatiza la idea de "co-instituir". Si se es fiel al sentido semántico de la expresión "poder constituyente", señala, éste debe ser concebido como la facultad humana y colectiva de inventarse políticamente. La comunidad tiene la facultad constituyente en forma inmanente, no derivada del derecho natural o de la voluntad divina. Al entender la soberanía como poder constituyente y no como mandato la participación se vuelve crucial, ya que es una acción imprescindible para co-instituir. Un nuevo orden constitucional debe ser creado por todos quienes quedarán sujetos a él, en tanto que sólo es válida una Constitución que cumple con los requisitos normativos de participación e inclusión (Kalyvas, 2005). Una Carta Fundamental que no sigue estos preceptos, como la chilena de 1980, no sería, en estricto rigor, una Constitución. Es la participación de los gobernados en su elaboración lo que diferencia al poder constituyente de un poder dictatorial (Friedrich, 1950).

La promoción de la participación ciudadana en Encuentros Locales Autoconvocados y Cabildos parece inspirada en una comprensión de que ella es necesaria para otorgar legitimidad a un proceso de cambio constitucional. Sin embargo, la expresión de preferencias en estos diálogos ciudadanos no reemplaza la necesidad de un mecanismo aceptado como democrático y representativo para la elaboración material de una nueva Carta Fundamental. Opciones como una comisión de expertos o una legislatura ordinaria, aquejada por graves problemas de legitimidad, no parecen los mecanismos apropiados para enfrentar este particular desafío.

Una asamblea constituyente, como órgano representativo creado explícitamente para elaborar la Constitución, parece la fórmula más democrática y legítima disponible (Elster, 2005). Una amplia participación no sólo en la elección de representantes, sino a través de la discusión pública y la movilización social, es componente fundamental de un sistema de representación. En lugar de entender representación y participación como modelos opuestos de democracia, Nadia Urbinati llama a superar la concepción dicotómica y entender la participación como parte esencial de un sistema de democracia representativa. No es un mecanismo que permite al representante tomar el lugar del representado, sino un proceso por medio del cual se pueden configurar las preferencias y al representado mismo, y que también puede activar y movilizar una identidad política. No se trata entonces de un pacto en que el representante actúa por una comunidad y una voluntad predeterminada, sino de aquello que genera esa comunidad y esas preferencias. (Urbinati, 2006).

Esta concepción de la representación política como acción requiere no sólo de la existencia de elecciones limpias y periódicas, sino de una enérgica sociedad civil en permanente interacción con las instituciones. La política se convierte en una 
arena donde las opiniones son discutibles y las decisiones, revisables. Los órganos de representación política no son, para Urbinati, un substituto de los representados en la esfera pública. El soberano simplemente no puede ser representado, por tanto los órganos representativos deben estar en una permanente tarea de "recrear" al pueblo y generar una sintonía que les permita actuar con legitimidad (Urbinati, 2006).

Las concepciones de Kalyvas y Urbinati sobre la soberanía como poder constituyente y no como comando y su reivindicación de la política extrainstitucional como parte de y no como amenaza a la democracia representativa, permiten incorporar a los movimientos sociales, a la opinión pública y a otras formas de participación ciudadana como parte integral de la democracia representativa.

En un escenario de reducidas posibilidades políticas, el proceso de diálogo constitucional ha abierto una posibilidad de instalar un "momento constituyente". Corresponde a la ciudadanía, con apoyo de los partidos y los organismos de la sociedad civil, conquistar a través de la participación política ese espacio para transformarlo en una fuerza capaz de generar un proceso constituyente democrático.

\section{NEOLIBERALISMO Y DERECHOS ECONÓMICO-SOCIALES}

El temor al pueblo, expresado en la concepción original de la Constitución de 19801, ha contribuido al creciente distanciamiento entre las instituciones y la ciudadanía. El Informe de Desarrollo Humano 2015 del Programa de Naciones Unidas para el Desarrollo mostró una abrumadora falta de sintonía entre las opiniones populares y aquellas sostenidas por las élites económicas y políticas (PNUD, 2015). Al mismo tiempo, el país exhibe una marcada tendencia a la baja en la identificación de las personas con partidos y coaliciones políticas. La imposibilidad de transformar preferencias en políticas públicas, producto de los blindajes de la Constitución de 1980, es un factor relevante en ese deterioro de la relación entre gobernantes y gobernados en Chile.

La primacía del derecho de propiedad en la Constitución por sobre cualquier otro - a la educación, a la salud o al uso del agua, por ejemplo- da cuenta del carácter neoliberal y autoritario de una Constitución inspirada en Friedrich Hayek

1. En su versión original, la Constitución garantizaba la mantención del statu quo por medio de la combinación de los senadores designados, el sistema electoral binominal y los altos quórums para reformar la Constitución o las 18 leyes orgánicas constitucionales. El Tribunal Constitucional contribuye a la irrelevancia del proceso político al actuar como una tercera cámara legislativa no electa y con capacidad de veto. 
y Carl Schmitt (Ruiz-Tagle y Cristi, 2006: 128). Por otro lado, la sistematización de las discusiones de unos nueve mil Encuentros Locales Autoconvocados a lo largo del país mostró una abrumadora tendencia a mencionar temas económico-sociales — salud, educación, vivienda y previsión social — como derechos que deben estar consagrados en la Constitución. Al respecto, las cartas fundamentales tienen tres opciones (Jung, 2011):

1. Pueden establecer derechos económico-sociales justiciables, es decir, los ciudadanos pueden presentar un recurso legal ante un tribunal, usualmente una corte constitucional, y el gobierno puede ser demandado por no garantizar un derecho económico y social prometido en la Constitución.

2. Pueden establecer derechos económico-sociales aspiracionales, una enumeración de derechos en la Constitución como principios que deben orientar las políticas públicas o como ideales, pero no como normas vinculantes. No crean obligación, los ciudadanos no los pueden reclamar judicialmente. Los derechos económicos y sociales no se consideran derechos fundamentales.

3. No mencionarlos en la Constitución.

En América Latina, los recursos de protección o amparo son considerados formas de reclamar el cumplimiento de derechos constitucionales. La Constitución chilena identifica claramente sólo algunos derechos como sujetos a recurso de protección, mientras que deja otros en el nivel de aspiracionales. Un estudio comparado de la Universidad de Toronto sobre derechos económicos y sociales en el mundo mostró una notoria diferencia entre ellos: el derecho a educación se encuentra consagrado en casi todas las constituciones, mientras que el derecho a la alimentación o el agua son muy infrecuentes. También identificó que las constituciones dan diferentes estatus a estos derechos. Un tercio de los países identifica todos los derechos económicos y sociales como justiciables, un tercio como aspiracionales y un tercio define algunos como justiciables y otros como aspiracionales. En esta última categoría se sitúa actualmente Chile.

El debate en el país ha presentado al menos tres posiciones. Primero, la versión neoliberal que sostiene que estos no son derechos como los civiles y políticos, y que depende de cada cual proveer su sustento material a través del mercado, ya que el Estado no debe involucrarse. Segundo, la versión de la Constitución mínima, que apunta al problema de judicialización de la política. Plantearlos como derechos constitucionales, dice esta posición, llevaría a que los jueces y no el Congreso determinen la política social. Esta postura no rechaza un papel del Estado en la economía, pero sostiene que ella no debe promoverse a través de derechos 
constitucionales. Por último, un tercer enfoque es partidario de consagrarlos en la Constitución como derechos fundamentales.

La primera posición, neoliberal, contradice la idea de que ciertas condiciones materiales de vida son derechos habilitantes de otros derechos. Va también en contra de la noción de que los derechos económicos y sociales son parte esencial de la noción de ciudadanía, como pertenencia a una comunidad política, con lo que ello implica en términos de derechos y también de deberes o responsabilidad hacia los conciudadanos. La definición de ciudadanía en términos de derechos civiles, políticos y sociales desarrollada en 1950 por Thomas H. Marshall es desestimada por la versión neoliberal.

La segunda posición rechaza entender estos derechos como análogos a los civiles y políticos por temor a su judicialización. En este caso no se trata de un rechazo general al papel del Estado en la provisión de bienes y servicios primarios — como salud, educación, vivienda—, sino a dejar en manos de los jueces y de la capacidad individual o colectiva de litigar, esta decisión. En cambio, se afirma que el proceso político normal, especialmente a través de leyes aprobadas en el Congreso, es el que debe definir estos temas. No es lo mismo garantizar derechos por efecto de litigios individuales que diseñar una política global de largo plazo.

En tercer lugar, entre quienes sí quisieran ver en una nueva Constitución la consagración de estos derechos se puede citar el programa de gobierno de la Nueva Mayoría: "La nueva Constitución deberá consagrar un estado social y democrático de derecho, que asume los derechos económicos, sociales y culturales como verdaderas obligaciones de la actividad estatal, para asegurar mínimos de igualdad social para un disfrute efectivo de todos los derechos". Agrega que el Estado social "protege el goce efectivo de derechos económicos, sociales y culturales" (Programa de gobierno Michelle Bachelet 2014-2018).

T.H. Marshall (1998) señaló que la ciudadanía plena implica el ejercicio de derechos civiles, políticos y sociales, pero que éstos no aseguran eliminar la desigualdad social. En tanto, algunas instituciones de derechos humanos han señalado que la desigualdad extrema constituye una amenaza a los derechos humanos en su conjunto. La discusión sobre derechos sociales y desigualdad no es ajena al tema de la distribución de poder que realiza una Constitución, porque existe una correlación entre desigualdad económica, social y cultural y desigualdad política (Lovera 2010). Los derechos establecidos en una Constitución —la llamada sección "dogmática" — no son independientes de la distribución de poder establecido en esa Carta, la sección orgánica.

En el contexto del debate sobre la ilegitimidad de origen y las falencias de la Constitución chilena de 1980, la pregunta crucial es cómo romper con una 
organización del poder que ha sido históricamente excluyente y que contribuye a aumentar las brecha de desigualdad.

Es posible que en la práctica la justicia juegue un papel positivo en la defensa de los derechos económicos, sociales y culturales, como ha ocurrido con las acciones sobre las isapres. Sobre todo, los jueces, constitucionales u ordinarios, pueden contribuir a instaurar un debate que involucre a los demás poderes del Estado y que lleve a una mayor inclusión. Sin embargo, para que un proyecto redistributivo afecte la desigualdad se necesita un cambio de reglas del juego que empareje la cancha tanto a nivel de las relaciones económicas, sociales y culturales como de la distribución institucional del poder político.

\section{CONCLUSIONES}

Las demandas por cambio constitucional se relacionan con un debate pendiente en la sociedad chilena sobre la desigualdad no sólo socioeconómica, sino en la distribución del poder político, sobre el papel del Estado en la economía y sobre el derecho a ciertas garantías sociales en materias como salud, educación, vivienda y previsión como parte de una concepción social de la ciudadanía. Este debate se ha visto reflejado en los contenidos de la fase llamada "participativa" del debate constitucional en curso, y también en múltiples expresiones de distanciamiento entre instituciones políticas y sociedad civil.

La sociedad chilena sufre un déficit democrático que se explica, al menos en parte, por la permanencia de instituciones diseñadas para dar la espalda a las preferencias políticas de la mayoría y consagrar el poder de veto de los herederos ideológicos de la dictadura militar. La más importante de esas instituciones es la Constitución de 1980.

Quienes sostienen que la Carta Fundamental debe ser reemplazada por un pacto político democrático concuerdan en que ello no es posible de acuerdo con las reglas institucionales vigentes, diseñadas para su preservación. El desafío entonces es encontrar un mecanismo que permita un acuerdo amplio y plural, donde pueda participar el conjunto de la sociedad chilena en un marco de deliberación democrática. El proceso iniciado en 2015 por el Gobierno de la Nueva Mayoría apunta a movilizar el capital político necesario para un cambio de esas características, generando un "momento constituyente" que no pueda ser desdeñado por las élites en el poder. 


\section{REFERENCIAS}

Ackerman, Bruce. (1991). We The People: Vol I, Foundations. Cambridge MA: Belknap Press.

Arato, Andrew. (2011). "Multi-Track Constitutionalism Beyond Carl Schmitt". Constellations 18:3.

Atria, Fernando. (2013). La constitución tramposa. Santiago: LOM.

Barros, Robert. (2002). Constitutionalism and Dictatorship. Pinochet, the Junta, and the 1980 Constitution. Cambridge: Cambridge University Press.

Correa Sutil, Jorge. (2015). "Proceso constituyente 'democrático, participativo e institucional': ¿ será posible?” en Chía y Quezada (Eds) Propuestas para una nueva Constitución (originada en democracia). Santiago: Instituto Igualdad, FES, Fac. Derecho U. Chile.

Elster, Jon. (1995), "Forces and Mechanisms in the Constitution-Making Process". Duke Law Journal 45: 2, 364-396.

Frank,Jason. (2010). Constituent Moments: Enacting the People in Postrevolutionary America. Durham, NC: Duke University Press.

Friedrich, Carl J. (1950). Constitutional Government and Democracy: Theory and Practice in Europe and America. Boston: Ginn and Company.

Fuentes S., Claudio. (2013). El Pacto. Poder, constitución y prácticas políticas en Chile (19902010). Santiago: Ediciones Universidad Diego Portales.

Fuentes, Claudio y Alfredo Joignant (Eds). (2015). La solución constitucional: plebiscitos, asambleas, congresos, sorteos y mecanismos hibridos. Santiago: Catalonia.

Godoy Arcaya, Óscar. (1999). "La transición chilena a la democracia: pactada." Estudios Públicos, 74.

Grez, Sergio y Foro por la Asamblea Constituyente. (2015). Asamblea constituyente: la alternativa democrática para Chile. Santiago: Editorial América en Movimiento.

Heiss, Claudia y Patricio Navia. (2007). "You Win Some, You Lose Some: Constitutional Reforms in Chile's Transition to Democracy". Latin American Politics and Society, 49:3, 163-190.

Huneeus, Carlos. (1997). "La autodisolución de la 'democracia protegida' en Chile. Cambios institucionales y el fin del régimen del General Pinochet”. Revista de Ciencia Política, Vol.19, Nº1. 
Jung, Courtney. (2011). "Coding Manual: a description of the methods and decisions used to build a cross-national dataset of economic and social rights in developing country constitutions". University of Toronto, Marzo 2011. Toronto Initiative for Economic and Social Rights, http:/ / wnw.tiesr.org/

Kalyvas, Andreas. (2005). "Soberanía popular, democracia y el poder constituyente". Política y gobierno. 12:1, 91-124.

Lijphart, Arend. (2000). Modelos de democracia: Formas de gobierno y resultado en treinta y seis países. Barcelona: Ariel.

Lovera, Domingo. (2010). "Derechos sociales en la Constitución del 80 (y de 1989 y de 2005)", en Fuentes S. (editor) En nombre del pueblo. Debate sobre el cambio constitucional en Chile. Ediciones Böll Cono Sur.

Marshall, Thomas H. (1998). Ciudadanía y clase social. Madrid: Alianza.

PNUD. (2015). Informe sobre Desarrollo Humano 2015: Los tiempos de la politización. Santiago: PNUD.

Programa de gobierno (2014-2018) Michelle Bachelet. bttp://michellebachelet.cl/ programal

Ruiz-Tagle, Pablo y Renato Cristi. (2006). La República en Chile. Teoría y Práctica del Constitucionalismo Republicano. Santiago: LOM

Urbinati, Nadia. (2006.) "Political Representation as a Democratic Process" Redescriptions: The Yearbook of Political Thought and Conceptual History. Vol 10, $18-40$.

Valdivia, Verónica. (2010). "Estabilidad y constitucionalismo: las sombras de la excepcionalidad chilena", en Fuentes S. (editor) En nombre del pueblo. Debate sobre el cambio constitucional en Chile. Ediciones Böll Cono Sur. 